\title{
El Estado y la memoria
}

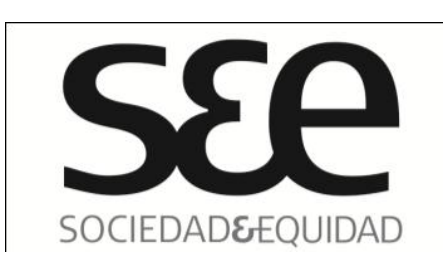

\begin{tabular}{ll} 
& State and memory \\
\hline Nombre: & Sandra Vera Gajardo (2) \\
Filiación: & Universidad de Barcelona \\
País: & España \\
Correo: & sandraveragajardo@gmail.com
\end{tabular}

\section{RESUMEN}

Se comenta el libro "El Estado y la memoria" en relación a los aportes que ofrece al análisis de las distintas experiencias de gestión del pasado en democracias postdictaduras. La problematización que hacen los autores en esta compilación de artículos, favorece la profundización de la teoría y prácticas en relación a la memoria que se hace en cada país. Asimismo, los autores advierten del cuidado en los abordajes de la memoria, pues determina el acontecer de los procesos democráticos en curso y, por lo tanto, puede abrir o cerrar posibilidades para el proceso político y social en su totalidad.

\section{PALABRAS CLAVES}

Memoria, transiciones políticas, administración de la memoria, democracia liberal.

\section{ABSTRACT}

The book "State and Memory" is discussed regarding the contributions that an analysis of different managements of experiences of the past in post-dictatorship democracies enables. The problematizations presented by the authors in this collection of articles, favors the deepening of theory and practice in relation to how memory is done in each country. Likewise, the authors advise the importance of a careful approach of memory, because this determines the development of ongoing democratic processes and can therefore open or close possibilities for all political and social processes.

\footnotetext{
${ }^{1}$ Vinyes, Ricard (2009). El Estado y la memoria. Gobiernos y ciudadanos frente a los traumas de la historia. Barcelona: RBA libros.

${ }^{2}$ La autora es Socióloga de la Universidad de Chile. Es doctoranda en Sociología por la Universidad de Barcelona y Master de Investigación en Sociología en esa misma universidad. Es miembro del equipo estable del "Observatorio del Conflicto Social, Barcelona" http://observatoridelconflicte.org/. Sus líneas de investigación son Movimientos sociales, transiciones políticas, acción colectiva, transición española, transición chilena.
} 


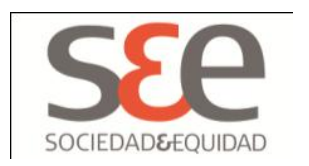

\title{
KEYWORDS
}

Memory, political transitions, memory management, liberal democracy.

\begin{abstract}
$* * *$
En las democracias de países que han pasado por dictaduras, transcurren una serie de conflictos, análisis y políticas públicas que asumen que existe un interés social por la recuperación de las heridas abiertas y los procesos de reconstrucción política y social inconclusos por el legado de distintas miserias (políticas, morales, penales) que ha dejado una dictadura.
\end{abstract}

Ricard Vinyes, como editor del libro El Estado y la memoria. Gobiernos y ciudadanos frente a los traumas de la historia, recoge las reflexiones de autores y autoras de variados países y disciplinas sobre lo que ocurre con este legado en los nuevos contextos democráticos y -específicamente- en relación con la forma en que el Estado, los gobiernos, las organizaciones y movimientos sociales gestionan el trato con el pasado fusionándolo con las posibilidades y limitaciones en el devenir de la democracia.

Vinyes señala que el criterio de los distintos artículos presentados en el libro fue justamente abordar estas problematizaciones de manera transversal y no como una simple recopilación para "mostrar lo que se había producido en un puñado de países" (Vinyes, 2009:16). Esta motivación -complementa el autor- "ha sido, pues, un criterio conducido por la voluntad de secularización de un tema con frecuentes derivaciones sagradas" (Vinyes, 2009: 16). El logro justamente de esta compilación de artículos es que el análisis y crítica que se hace de la gestión de la memoria en las distintas experiencias, obliga a comparar y a comprender cada caso desde una problematización integral y compleja de las sociedades.

Desde este énfasis, podemos seguir algunos focos de análisis presentados a lo largo de la obra, y de esta manera comentar los puntos que aportan a profundizar los matices y nudos en relación a los estudios y prácticas de las memorias postdictaduras.

Lo primero que se puede destacar es la ineludible necesidad de hablar de la memoria de las transiciones políticas para poder hacer un tratamiento más profundo de la memoria de la dictadura. Esto implica hablar de las decisiones deliberadas que ocurrieron en ciertas transiciones -en la cual se destaca la de España- para que el olvido fuera un deber de la ciudadanía en contribución a un proceso político que se entiende carente de otra posibilidad de obtener una resolución pacífica para poner fin a una dictadura (Domenech, en Vinyes, 2009: 431). Existe la tentación de generalizar todas las transiciones políticas en sus técnicas del olvido; sin embargo, al 


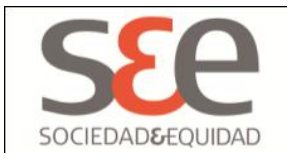

profundizar cada proceso en su especificidad, no se puede dejar de destacar que en algunos lugares estas operaciones significaron renunciar a la penalización de los responsables y en otros lugares no. Esta diferencia no es menor al querer hablar del tratamiento del pasado y los límites de las democracias postdictatoriales. Como se señaló, el caso español es emblemático en esta situación, lo cual es explicado en el artículo de Pere Ysàs en la descripción que realiza del proyecto político del "antifranquismo" como parte de una transición que supeditaba todo al objetivo primordial que era acabar con 40 años de franquismo:

la transición española no comportó la exigencia de responsabilidades penales para la violación de los derechos humanos y hoy, treinta años después, este hecho provoca tanta sorpresa como interpretaciones equivocadas entre quienes desconocen el proceso. Para el antifranquismo, la no exigencia de responsabilidades no fue una renuncia impuesta por unas condiciones difíciles -por otro lado, ciertas- y con amenazas constantes de involución; sencillamente este objetivo estaba ausente en su proyecto ( $P$. Ysàs, en Vinyes, 2009: 395).

Para Vinyes esto significó sustituir un "espacio de referencia ético" por un mito que nombra como "la transición modélica" (Vinyes, 2009: 25-26). En el caso de España esto fue un relato que se materializó en una ley: la ley de Amnistía de 1977 que estableció la impunidad equitativa. En el caso de otros países el mito de la "transición modélica" pudo haber sido relatado con las mismas u otras narrativas. Sin embargo, lo importante es que sugiere la obligación de hablar de las operaciones de la transición política como determinantes de largo alcance en las nuevas democracias. Es más, quizás obliga también a calificar a las sociedades de las que estamos hablando como sociedades "postransicionales" y no solo "postdictatoriales", pues la marca para el proceso político posterior es doble.

En la misma línea pero abriendo otras preguntas, cabe destacar las causas y consecuencias que se señalan en relación a la memoria de la transición. Éstas se explican en lo que se nombra desde distintos artículos como la "administración de la memoria", lo cual es tratado de manera crítica por las tendencias a la "proliferación de un sentimiento nostálgico pretendidamente apolítico y sustentado por criterios morales del liberalismo reinante, que se convierte en la base legitimadora de una industria de la memoria" que puede derivar en "la obsesión por la musealización global", y podría acabar "imponiendo un pasado mítico por encima del pasado real" (Font, en Vinyes, 2009: 380-381). Ahora bien, la lectura de los distintos artículos posibilita diferenciar los problemas y situaciones en cuanto a la administración de la memoria: por un lado está el problema de que la memoria del pasado traumático sea un simple "deseo administrativo", "un proceso institucional y no social" (Vinyes, 


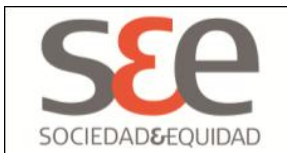

2009: 26), y por otro lado está la tensión -que ha enriquecido solo algunos procesos democráticos- sobre quienes han liderado esta administración. Es aquí donde es acentuada la diferencia de las dictaduras del Cono Sur de América Latina, donde el movimiento de derechos humanos ha sido el actor privilegiado (Jelin, en Vinyes, 2009: 124). Este punto es una constatación del peso que tiene la acción de los movimientos sociales en relación a la verdad y justicia post-dictatorial, pero también es lo que permite que se exhiba otra profunda cuestión en relación a lo complejo que es hablar del Estado como responsable de una política pública de memoria y que sea quien lidere una especie de bosquejo de lo que se recuerda. Es así que se presentan quienes hacen un llamado a cuidarse de hablar de la memoria como un valor en sí mismo, sin distinguir que hay memorias con distintos apellidos que no siempre corresponden al valor que se pretende defender. Elizabeth Jelin explica claramente esta necesaria precaución:

el espacio de la memoria es entonces un espacio de lucha política, y no pocas veces esta lucha es concebida en términos de lucha "contra el olvido": recordar para no repetir. Las consignas pueden ser en este punto algo tramposas. La "memoria contra el olvido" o "contra el silencio" esconde una oposición entre memorias rivales. Es en verdad "memoria contra memoria", cada una de ellas con sus silencios, huecos y olvidos (Jelin, en Vinyes, 2009: 119).

Desde distintos autores se señalan advertencias críticas a la idea del "rescate de la memoria democrática"; por ejemplo, por la posibilidad de que la manera en que ésta se desarrolle armonice con una democracia liberal que en nada contribuye al enriquecimiento de un proceso social profundo. Para J. Font esto ocurre cuando se presenta el pasado "como algo cerrado y separado de nuestras vidas", donde vemos a unos "actores de los cuales podemos compadecernos celebrando nuestra buena suerte al haber superado una frase pretérita con la que ya no tenemos ninguna clase de nexo" (Font, en Vinyes, 2009: 380). Para Font esto es promovido a través de la "visión estetizada del testimonio", que es promovida por "el buenismo liberal" y que hace privilegiar la visión emotiva y nostálgica de los horrores por sobre el compromiso político. Este "anacronismo de la democracia liberal" deviene en desmovilización (Font, en Vinyes, 2009: 388). Isabel Piper advierte también de esta situación que "las memorias de la dictadura operan como tecnologías que producen al sujeto víctima", y que en el caso de Chile brinda la ocasión de que ocurra que "las memorias de la dictadura chilena han ido transformando a los protagonistas de sus luchas políticas en dolientes y por esta vía los ha despojado de su fuerza política. Su problematización tendría que ser capaz de devolverle el lugar de actores sociales (Piper, en Vinyes, 2009: 153-154). Y continúa la idea señalando que "cuando la tragedia de la víctima se transforma en el guión que dirige las prácticas de las 


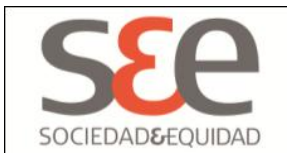

memorias hegemónicas de una sociedad, difícilmente se logran generar nuevos campos de acción política y se corre el riesgo de quedar condenados al trauma y atrapados a la marca del sufrimiento" (Piper, en Vinyes, 2009: 160).

En definitiva, las visiones de los distintos autores en el libro señalado procuran distinguir y hacer las críticas y matices pertinentes para no señalar el "deber de memoria" con discursos limitados o como un imperativo que no necesitara ser problematizado. Las respuestas a la relación entre el Estado y la memoria son una de las encrucijadas que son convocadas a re-pensarse. Es así como la idea de "reparación" se señala como inacabada en su planteamiento. En este sentido, Isabel Piper subraya que al ser la memoria una práctica de resistencia donde no debe estar en juego solo las interpretaciones del pasado, sino también el futuro posible, "no se trata de corregir el pasado ni de restituir lo perdido. Se trata de transformar nuestra sociedad para que las dictaduras militares no sean posibles" (Piper, en Vinyes, 2009: 160-161). Vinyes por su parte afirma que "el daño causado por una dictadura es irreparable. (...) Tan sólo ha de ser explicado, reconocido y asumido con todas las consecuencias que la sociedad, dotada de un Estado de derecho, establezca" (Vinyes, 2009: 59).

\section{Referencias Bibliográficas}

Vinyes, Ricard (2009) El Estado y la memoria. Gobiernos y ciudadanos frente a los traumas de la historia. Barcelona: RBA libros. 